\title{
Sleep Problems in Early Childhood and Early Onset of Alcohol and Other Drug Use in Adolescence
}

\author{
Maria M. Wong, Kirk J. Brower, Hiram E. Fitzgerald, and Robert A. Zucker
}

\begin{abstract}
Background: No prospective studies exist on the relationship between sleep problems early in life and subsequent alcohol use. Stimulated by the adult literature linking sleep problems to the subsequent onset of alcohol use disorders in some adults, we examined whether sleep problems in early childhood predicted the onset of alcohol and other drug use in adolescence and whether such a relationship was mediated by other known predictors of this relationship, namely, attention problems, anxiety/depression, and aggression in late childhood.

Methods: This study is part of an ongoing longitudinal study of the development of risk for alcohol and other substance use disorders. Study participants were 257 boys from a community-recruited sample of high-risk families.

Results: Mothers' ratings of their children's sleep problems at ages 3 to 5 years significantly predicted an early onset of any use of alcohol, marijuana, and illicit drugs, as well as an early onset of occasional or regular use of cigarettes by age 12 to 14 . Additionally, although sleep problems in early childhood also predicted attention problems and anxiety/depression in later childhood, these problems did not mediate the relationship between sleep problems and onset of alcohol and other drug use.

Conclusions: This is, to our knowledge, the first study that prospectively examines the relationship between sleep problems and early onset of alcohol use, a marker of increased risk for later alcohol problems and alcohol use disorders. Moreover, early childhood sleep problems seem to be a robust marker for use of drugs other than alcohol. Implications for the prevention of early alcohol and other drug use are discussed.

Key Words: Sleep Problems, Alcohol Use, Drug Use, Onset of Alcohol Use, Onset of Drug Use.
\end{abstract}

$\mathbf{S}^{\mathbf{L}}$ LEEP PROBLEMS, PRIMARILY insomnia, have been shown to predict subsequent onset of alcohol disorders among some adults [reviewed in Brower (2001)], but the processes by which this relationship has evolved remain unknown. Work by Roehrs et al. (1999) demonstrated that insomniacs were more likely than controls to choose an alcoholic versus placebo beverage at bedtime, suggesting that alcohol may be more reinforcing in insomniacs than controls. Moreover, although the connection between sleep problems and alcohol disorders has aroused considerable interest among adult alcoholism researchers, the possibility that sleep problems may play a causal role in the onset of alcohol problems, alcoholism, and other drug involvement has been largely overlooked in the child and adolescent literature. No prospective studies exist on the relationship between sleep problems and alcohol use early

From the Departments of Psychiatry (MMW, KJB, RAZ) and Psychology (RAZ), University of Michigan, Ann Arbor, Michigan; and Department of Psychology (HEF), Michigan State University, East Lansing, Michigan.

Received for publication June 30, 2003; accepted December 18, 2003.

Supported in part by NIAAA Grants R37 AA07065 (RAZ and HEF) and K24 AA00304 (KJB).

Reprint requests: Maria M. Wong, PhD, University of Michigan Addiction Research Center, Department of Psychiatry, 400 E. Eisenhower Pkwy., Ste. 2A, Ann Arbor, MI 48108; Fax: 734-615-6085; E-mail: mmwong@umich.edu.

Copyright (c) 2004 by the Research Society on Alcoholism.

DOI: 10.1097/01.ALC.0000121651.75952.39 in life. However, cross-sectional studies suggest that sleep problems are positively related to substance use in adolescence (e.g., Johnson and Breslau, 2001; Tynjala et al., 1997; Vignau et al., 1997). This study prospectively examined the relationship between sleep problems (i.e., insomnia) and drug use in adolescence and also probed for some plausible mediators of that relationship.

Insomnia-i.e., difficulty falling asleep, staying asleep, or feeling tired and not refreshed in the morning, causing the sleeper to feel distress or impairment (American Psychiatric Association, 2000; American Sleep Disorders Association, 1997) - has been shown to predict alcohol problems among some adults (Brower, 2001). Using data from the Epidemiologic Catchment Area study $(n=7954)$, Ford and Kamerow (1989) found that individuals who had persistent insomnia from baseline to 1 year were 2.4 times more likely than individuals without insomnia to develop a new incident of alcohol abuse 1 year later. However, because the analyses did not control for psychiatric disorders at baseline, the relationship between insomnia and alcohol abuse could have been due to the presence of other psychiatric disorders. Weissman et al. (1997) reanalyzed the Epidemiologic Catchment Area data and included only adults without a psychiatric disorder at wave $1(n=5240)$. They found that individuals with insomnia were 2.3 times more likely than those without insomnia to experience the first onset of 
alcohol abuse at wave 2. Breslau et al. (1996), using a sample of 979 participants from a southeast Michigan health maintenance organization, reported a nonsignificant trend for an effect of prior insomnia on subsequent onset of alcohol abuse or dependence (odds ratio, 1.72). However, the results of all three studies are in the same direction. It is useful to note that in the Breslau study, the relationship between insomnia and other drug use was significant. Individuals with insomnia were 2.4 times more likely to experience the onset of nicotine dependence and 7.2 times more likely to experience the onset of drug abuse or dependence. It is possible that insomnia may contribute to the development of other substance use disorders and not only alcohol abuse and dependence.

The effects of alcohol on sleep may contribute directly to the development of alcohol problems. Some individuals are motivated to use alcohol because of its effects on reducing initial sleep latency. Almost one in five adults (19\%; $26 \%$ among those between 18 and 29 years old) have used alcohol to help them sleep (National Sleep Foundation, 2000). In an epidemiological study of 2181 adults in the Detroit metropolitan area, Johnson et al. (1998) found that $13 \%$ had used alcohol to help them sleep in the previous year. In a clinical sample, Brower et al. (2001) reported that $44 \%$ of 172 alcoholics in treatment often used alcohol to aid sleep. Yet laboratory studies indicate that acute and chronic alcohol ingestion generally disrupts sleep patterns during the night, despite alcohol's initial sedative effects (Brower, 2001; Roehrs and Roth, 2001). Moreover, individuals can develop tolerance over time to the sedative effects of alcohol. The combination of tolerance and sleep disruption can lead to escalations in drinking amounts and problems (Roehrs and Roth, 2001).

Finally, insomnia has been shown to be a good predictor of relapse among patients undergoing treatment for alcohol dependence in at least five analyses of three study samples (Brower et al., 1998, 2001; Foster et al., 1998; Foster and Peters, 1999; Skoloda et al., 1979). These findings hold even while controlling for demographic and clinical covariates such as age, gender, and depressive symptoms. Polysomnographic measures of disturbed sleep also predict alcoholic relapse (Brower, 2001; Landolt and Gillin, 2001).

Relatively little is known about the relationship between sleep problems and alcohol use in adolescence. This is a particularly interesting developmental period because changes in both sleep/sleep habits (National Sleep Foundation Sleep and Teens Task Force, 2000) and alcohol use (Johnston et al., 2002) occur during this time. The prevalence of sleep problems among adolescents and young adults is high and is increasing (National Sleep Foundation Sleep and Teens Task Force, 2000).

A number of changes in sleep/sleep habits occur in adolescence. These changes include decreases in the amount of rapid eye movement sleep and slow-wave sleep, greater daytime sleepiness, and tendencies to shift to a later bedtime and waking time (phase delay), to develop irregular sleep patterns, and to not get enough sleep (Carskadon et al., 1993; Dahl and Carskadon, 1995; Wolfson and Carskadon, 1998). Some of these changes, such as phase delay, may be related to biological changes associated with puberty (Carskadon et al., 1993). Psychosocial factors also play a role, including decreases in parental monitoring and increases in time spent with peers, homework, extracurricular activities, and job commitments (NIAAA, 2000).

As noted previously, there are currently no longitudinal studies on the relationship between sleep problems and alcohol use (or substance use in general) in children and adolescents. Several cross-sectional studies indicate that sleep pattern irregularities and sleep problems may be associated with increased alcohol use. As part of the World Health Organization-coordinated survey of school children's health behavior, Tynjala et al. (1997) found an association between later and more irregular sleep schedules, perceived daytime tiredness, and increased use of cigarettes and alcohol in 1057 15-year-old Finnish adolescents. In a sample of French secondary school students, Vignau et al. (1997) reported bivariate associations between being a poor sleeper (defined as insomnia, needing more sleep than others, and use of sleeping pills) and use of alcohol, cigarettes, and illicit drugs. Using data from the US National Household Survey on Drug Abuse, Johnson and Breslau (2001) found a positive relationship between selfreports of often having trouble sleeping and use of alcohol, cigarettes, and any illicit drug in 13,381 adolescents aged 12 to 17 years. Controlling for internalizing (e.g., depression) and externalizing (e.g., aggression) problems reduced the associations between sleep problems and drug use. However, the relationship between sleep problems and use of alcohol on 12 or more days remained significant, as did the relationship between sleep problems and the use of illicit drugs together with alcohol and/or cigarettes. These findings may reflect the tendency for sleep problems, substance use, and psychiatric problems to co-occur in the same individuals during adolescence.

Because cross-sectional studies do not allow for testing of temporal order, it is impossible to infer the causal relationship between sleep problems and alcohol use. Moreover, many cross-sectional studies did not separately analyze the relationship between sleep problems and alcohol involvement before and after use and problems began. Once onset occurs, excessive use of alcohol (e.g., binge drinking and drunkenness) may lead to sleep disturbances, which can start a vicious cycle of drinking to aid sleep, more sleep disturbances, and more drinking. Thus, it is important to take into account the reciprocal relationship of these two factors (Brower, 2001; NIAAA, 1998). Such relationships can be investigated only prospectively.

Externalizing problems (e.g., aggression and delinquency) have been shown to predict alcohol use and problems in many studies (e.g., Caspi et al., 1996; Chassin et al., 1999; Donovan and Jessor, 1985). There is also substantial evidence that attention problems are a risk factor for pre- 
cocious substance use (Pihl and Bruce, 1995; Pihl and Peterson, 1991). Empirical support for the relationship between internalizing problems (e.g., depression and anxiety) and alcohol use has been less consistent (Wong MM, Zucker RA, Stoltenberg S (2003) The relation between depression and the development of alcohol problems. Submitted.) (Hussong et al., 2001; Zucker, 1994). Internalizing problems probably predict alcohol use and problems only in certain populations, e.g., women (Helzer et al., 1991), and more generally among those who believe in the effects of alcohol for regulating negative affect (Cooper et al., 1992; Sher, 1994).

In addition, attention problems, externalizing problems, and internalizing problems are all associated with sleep problems. Sleep disturbances seem to decrease one's ability to regulate, control, or inhibit emotion and behavior (Dahl, 1996; Wolfson and Carskadon, 1998). Thus, poor sleep may contribute to an increased level of these problems. For instance, depressed individuals often have trouble sleeping, and insomnia is a well established symptom of depression (Beck et al., 1988; Hamilton, 1969). Insomnia has also been shown to precede depression in adults (Chang et al., 1997; Eaton et al. 1995). Inattention and hyperactivity were associated with sleep-related breathing disorders among children referred to sleep centers (Guilleminault et al., 1981, 1982) and children who were seen in child psychiatry and general pediatrics clinics (Chervin et al., 1997). Conduct problems were positively related to symptoms of sleepdisordered breathing, restless leg syndrome, or periodic leg movements during sleep (Chervin et al., 2003).

We examined the relationship between sleep problems in early childhood and the onset of alcohol and other drug use in early adolescence. Additionally, we ascertained whether such a relationship was mediated by attention and behavioral problems in late childhood. We used a high-risk sample of children of alcoholics and matched controls who lived in the same neighborhoods as the alcoholics (Zucker et al., 2000).

\section{METHODS}

\section{Participants}

This study is part of an ongoing longitudinal family study of the development of risk for alcohol and other substance use disorders (Zucker and Fitzgerald, 1991; Zucker et al., 1996, 2000). The larger study recruited a population-based sample of 311 alcoholic men, their partners (whose substance abuse status was free to vary), and their initially 3- to 5-year-old sons.* Alcoholic men were identified by population sampling methods involving a canvass of all courts in a four-county-wide area for drunk drivers with high blood alcohol levels and a neighborhood canvass in the areas where the court alcoholics lived, to recruit additional alcoholics. The

* The 3- to 11-year-old daughters in the families were also invited to participate in the longitudinal study after the study began. Most of these girls joined the project at ages 6 to 11; i.e., they missed the time 1 data collection wave. More recently, the study has recruited an additional sample of girls that begins at time 1. We plan to analyze those data as soon as they become available. neighborhood canvass recruited a control group of families who resided in the same neighborhood as the alcoholic families but whose parents had no lifetime history of substance abuse or dependence. Offspring of control families were age-matched to the male child in the alcoholic family residing in the same neighborhood [for a detailed description of recruitment strategies and eligibility criteria, see Zucker et al. (1996, 2000)]. Both biological parents were required to be living together in the same household (either as married couples or domestic partners) and to have a 3- to 5 -year old son living with them at the time of recruitment. The presence of fetal alcohol syndrome was an exclusionary criterion (Fitzgerald et al., 1993, 1995). Analyses of benchmark indicators reported in Zucker et al. (2000) show that the level of psychiatric comorbidity among alcoholic men in this sample was higher than in the general US population of alcoholics but somewhat lower than that found in clinical populations.

The current sample consists of 258 initially preschool-aged boys and both of their biological parents ( $60 \%$ alcoholic families and $40 \%$ controls), who were selected from the original study on the basis of the criterion that they provided drinking and other drug use information when they were 12 to 14 years old. Respondents were interviewed at 3-year intervals. The boys were 3 to 5 years old at time 1 (T1), 6 to 8 years old at time 2 (T2), 9 to 11 years old at time 3 (T3), and 12 to 14 years old at time 4 (T4). Of the 258 participants, $219(85 \%)$ provided data at T3, when funding difficulties systematically precluded evaluation of a subset of participating families.

This missingness fits the description of data missing at random (MAR) (Little and Rubin, 1987; Rubin, 1976; Schafer and Graham, 2002). Data are MAR if the distribution of missingness depends on the observed data rather than on the missing data (Rubin, 1976; Schafer and Graham, 2002). This is to be distinguished from data missing completely at random, i.e., the missing values are a random subsample of the entire dataset and are not dependent on either the observed or the missing data. Planned missingness, where the missing data are not intended to be collected, is known to meet the assumptions of either missing completely at random or MAR, depending on how the researchers planned the missingness. If data are not collected from the respondents on the basis of certain criteria, e.g., an observed characteristic known to the researcher, then the assumptions for MAR hold. In the Michigan Longitudinal Study, data from some families (e.g., those with children too old for the study wave) were not collected because of funding constraints. This type of missingness fits the assumption of MAR. The data were imputed by the expectation-maximization algorithm. The algorithm estimates missing data by using an iterative process and is superior to methods such as mean-substitution and regression imputation (Graham and Hofer, 2000).

All families were Caucasian Americans. In the study sampling area, less than $4 \%$ of the population meeting inclusion criteria was non-Caucasian. Given the study's sample size, if non-Caucasian ethnic/racial groups were included, the number available would not permit any effective analysis. Because there is an extensive literature showing a relationship between substance abuse and ethnic/racial status, including such variation in the study without being able to statistically model its effects would only contribute to error. Therefore, the investigators originally opted to exclude this variation. The study is currently recruiting an additional sample of both African American and Hispanic families by using parallel recruitment criteria.

\section{Procedures}

Trained interviewers who were blind to family diagnostic status collected the data. The contact time for each family varied, depending on the data collection wave. Typically, each parent was involved for 9 to $10 \mathrm{hr}$ and each child for $7 \mathrm{hr}$ spread over seven sessions. A variety of age-appropriate tasks (e.g., questionnaires, semistructured interviews, and interactive tasks) were administered, and most of the contacts occurred in the families' homes. Special arrangements were made to collect data from families who had relocated. No families were lost because of relocation. 


\section{Measures}

Sleep problems in early childhood (ages $3-5$ years) were measured by mothers' ratings on the Child Behavior Checklist-Parent Version (CBCL) (Achenbach, 1991). The CBCL is a widely used instrument that measures common behavioral problems among children. Its reliability and validity have already been demonstrated (Achenbach, 1991; Achenbach and Edelbrock, 1983). Two items were used to indicate sleep problems: overtiredness and having trouble sleeping. Responses to each item were scored on a three-point rating scale $(0=$ not true; $1=$ somewhat or sometimes true; $2=$ very true or often true). A relatively small percentage of the sample had a score of 2 on either item (for trouble sleeping, $7.6 \%$ had a score of 1 and $4.4 \%$ had a score of 2; for overtiredness, $25.9 \%$ had a score of 1 and $2 \%$ had a score of 2$)$. Therefore, each item was recoded as a dichotomous variable $(0=$ not true; $1=$ sometimes or often true $)$. Children who were rated as having problems sleeping were also more likely to be rated as overtired $\left[\chi^{2}(1)=14.03 ; p<0.001\right]$. Given this relationship, the two items were combined to form a composite indicator of sleep problems $(0=$ absence of either problem; 1 = presence of either problem). The effects of the two sleep items and the composite indicator on drug use were examined separately in the analyses.

Attention problems in late childhood (ages 9-11) were measured by mothers' ratings of the attention problems subscale on the CBCL (Achenbach, 1991). This subscale consists of 11 items (e.g., cannot concentrate, cannot sit still; Cronbach $\alpha=0.72$ ). Anxiety/depression problems in late childhood (ages 9-11) were measured by mothers' ratings of the anxiety/ depression subscale of the CBCL (Achenbach, 1991). There are 14 items in this subscale (e.g., feels worthless, complains of loneliness, cries a lot; Cronbach $\alpha=0.77$ ) Aggression in late childhood (ages 9-11) was measured by mothers' ratings of the aggressive behavior subscale of the CBCL (Achenbach, 1991). The subscale consists of 20 items (e.g., gets in fights, physically attacks people, bullies; Cronbach $\alpha=0.87$ ).

Drinking and drunkenness in early adolescence (ages 12-14) were assessed by the Drinking and Other Drug Use History QuestionnaireYouth Version (DDHQ-Y; Zucker and Fitzgerald, 2002). All of the items have been extensively used in a variety of survey and clinical settings. The questionnaire measures the frequency and quantity of alcohol use and problems and the frequency of other drug use and problems. Two items were used to assess the onset of drinking and drunkenness: "How old were you the first time you ever took a drink (not just a sip)?" and "How old were you the first time you drank enough to be drunk?" From these responses, information on early onset of drinking and drunkenness was generated $(0=$ absence of use by ages $12-14 ; 1=$ presence of use by ages 12-14). Early onsets of drinking and drunkenness have been shown to be very robust predictors of subsequent alcohol problems (Grant and Dawson, 1997; Gruber et al., 1996).

Cigarette, marijuana, and other drug use in early adolescence (ages 12-14) were also measured by the DDHQ-Y. In addition to cigarettes and marijuana, the DDHQ-Y also asked questions about use of illicit drugs. These included inhalants (e.g., glue and aerosol spray), amyl or butyl nitrites, amphetamines, lysergic acid diethylamide and other psychedelic drugs, crack and other forms of cocaine, anabolic steroids, tranquilizers such as methaqualone (Quaaludes), heroin, and opioids other than heroin. Lifetime use of cigarettes was indicated by the item, "Have you ever smoked cigarettes?" More than a quarter of the participants (28\%) reported having smoked cigarettes. Because being an occasional or regular smoker (i.e., those who smoked more than once or twice) presented a more serious health risk than smoking once or twice in one's lifetime, we coded the cigarette use variable so that nonusers and those who used cigarettes only once or twice were put in the same group, whereas those who used cigarettes occasionally or regularly were put in another group. Lifetime use of marijuana was measured by the question, "On how many occasions (if any) have you smoked marijuana or hashish in your lifetime?" Questions about the use of other illicit drugs were worded similarly. From these items, information about early onset of use for each drug was coded 0 for absence of use by age 12 to 14 and 1 for presence of use by age 12 to 14 .
Parental alcoholism when children were 3 to 5 years of age was assessed by the Short Michigan Alcohol Screening Test (Selzer et al., 1975), the Diagnostic Interview Schedule Version III (Robins et al., 1980), and the Drinking and Drug History Questionnaire (Zucker et al., 1990). Both fathers and mothers independently provided information on all three instruments. On the basis of this information, a diagnosis of alcohol abuse or dependence in the past 3 years was made by a trained clinician using DSM-IV criteria (a lifetime diagnosis was also made but was not used in this study). The diagnosis was scored as follows: $0=$ no diagnosis, $1=$ alcohol abuse, 2 = alcohol dependence without physical dependence, and 3 = alcohol dependence with physical dependence. The interrater reliability for this measure was 0.81 . A score of parental alcoholism was created from these diagnoses $-0=$ no diagnosis in either parent in the last 3 years or $1=$ alcohol diagnosis (abuse or dependence) in either parent in the last 3 years.

\section{Analytical Plan}

We first ascertained whether early childhood sleep problems predicted an early onset of drinking, drunkenness, and other drug use in adolescence. Parental alcoholism and age (respondents were between the ages of 12 to 14 years) have been shown to predict these outcomes; therefore, their effects on substance use were controlled for in the analyses. Because outcomes were dichotomous ( $0=$ absence of use; $1=$ presence of use $)$, logistic regression models were performed to estimate the effect of sleep problems on substance use while holding constant the effects of parental alcoholism and the child's age, i.e., estimating the relationship between sleep problems on substance use in the presence of parental alcoholism and age. Five series of logistic regression models were estimated, corresponding to each of the five outcome variables: early onset of drinking, drunkenness, occasional or regular cigarette use, marijuana use, and illicit drug use (i.e., marijuana and other drugs excluding alcohol and cigarettes). We combined all illicit drugs into one category because of the low rate of use for each drug other than marijuana (range, $0-5.7 \%$ ). In each series, separate analyses were run for each of the three predictor sleep variables: trouble sleeping, overtiredness, and the composite indicator of sleep problems (either trouble sleeping or overtiredness).

Following Baron and Kenny (1986), a number of steps were taken to estimate whether attention problems, anxiety/depression, or aggression in late childhood mediated the effect of early childhood sleep problems and adolescent substance use. First, we ascertained the effects of sleep problems on each outcome while controlling for parental alcoholism and age. If a significant relationship was established, we proceeded to the second step-examining whether the effects of sleep problems on each potential mediator were significant. Because these mediators were correlated with one another, their effects were tested in separate models. Third, we ascertained the effect of each mediator on the outcomes while holding constant the effect of sleep problems. Fourth, we estimated the effect of sleep problems on the outcomes while the mediators were held constant. Evidence of mediation was observed when the effect of sleep problems on the outcomes decreased (partial mediation) or disappeared (full mediation) in the presence of the mediator. Because of the possible nonlinear relationship between the mediators and the outcomes (e.g., only children with more severe behavioral problems may develop substance use), in addition to using each mediator as a continuous variable, each was also evaluated as a dichotomous variable. Using the 75th percentile scores as the cutoff, we separated children into groups of low and high attention problems, anxiety, and aggression.

\section{RESULTS}

Descriptive statistics on all variables are presented in Table 1 . Close to two thirds $(60.3 \%)$ of the children in the study had at least one alcoholic parent. At ages 3 to 5, more than one tenth of children were rated as having trouble sleeping and more than one quarter were rated as over- 
Table 1. Descriptive Statistics on All Variables $(n=257)$

\begin{tabular}{lccccc}
\hline \multicolumn{1}{c}{ Variable } & $\begin{array}{c}\% \\
\text { Yes }\end{array}$ & Mean & SD & \multicolumn{1}{c}{ Range } \\
\hline $\begin{array}{c}\text { Sleep problems: two-item composite } \\
\quad \text { index (at 3-5) }\end{array}$ & 33.5 & - & - & 0 (no) to 1 (yes) \\
$\quad$ Trouble sleeping (at 3-5) & 12.5 & - & - & 0 (no) to 1 (yes) \\
$\quad$ Overtired (at 3-5) & 27.6 & - & - & 0 (no) to 1 (yes) \\
Parental alcoholism (at 3-5) & 60.3 & - & - & 0 (no) to 1 (yes) \\
Attention problems (at 9-11) & - & 3.08 & 2.40 & $0-13$ \\
Anxiety/depression (at 9-11) & - & 2.94 & 2.67 & $0-17$ \\
Aggression (at 9-11) & - & 8.27 & 5.09 & $0-31$ \\
Onset of drinking (by 12-14) & 31.9 & - & - & 0 (no) to 1 (yes) \\
Onset of drunkenness (by 12-14) & 12.8 & - & - & 0 (no) to 1 (yes) \\
Onset of occasional or regular & 12.1 & - & - & 0 (no) to 1 (yes) \\
$\quad$ cigarette use (by 12-14) & & & & \\
Onset of marijuana use (by 12-14) & 12.9 & - & - & 0 (no) to 1 (yes) \\
Onset of illicit drug use (by 12-14) & 17.10 & - & - & 0 (no) to 1 (yes) \\
$\quad$ (i.e., marijuana and other drugs) & & & & \\
Age (at 12-14) & - & 14.11 & 0.74 & $11.83-14.99$ \\
\hline
\end{tabular}

tired. One third $(33.5 \%)$ of the children had either sleep problem. Having an alcoholic parent did not significantly increase the risk of childhood sleep problems $\left[\chi^{2}(1)=\right.$ 0.33 ]. In addition, parental alcoholism at ages 3 to 5 was not significantly related to attention problems $[t(255)=$ $-0.60]$, anxiety/depression $[t(195.01)=0.27]$, or aggression $[t(255)=-1.11]$ at ages 9 to 11 . By ages 12 to 14 , close to one third of the participants $(31.9 \%)$ had started drinking. Of those who drank, more than one third $(40.2 \%)$ reported being drunk at least once. Approximately one tenth of all participants regularly smoked cigarettes (i.e., used more than once or twice), and $17.1 \%$ had used at least one kind of illicit drug other than alcohol. Table 2 presents the number of participants who had childhood sleep problems and the onset of adolescent alcohol and other drug use.

As expected, parental alcoholism and the child's age at T4 predicted the onset of drinking, drunkenness, marijuana use, and other drug use (Table 3). Occasional or regular use of cigarettes was predicted by age, but not by parental alcoholism. Controlling for the effect of parental alcoholism and the child's age, the presence of early childhood sleep problems (composite indicator) significantly predicted the onset of drinking, regular cigarette use, marijuana use, and illicit drug use (Table 3). When compared with children without sleep problems, those with sleep problems in early childhood were 2.3 times more likely to have started using alcohol by ages 12 to 14 . These children were also 2.3 times more likely than others to be occasional or regular smokers. Moreover, when compared with their counterparts, they were 2.6 times more likely to have used marijuana and 2.2 times more likely to have used illicit drugs. Sleep problems did not have a significant relationship with onset of drunkenness.

The relationship between each individual sleep item and the onset of substance use was weaker (Table 3). Having trouble sleeping in childhood was significantly related to onset of drinking in adolescence. Overtiredness in childhood significantly predicted the onset of drinking, use of marijuana, and use of illicit drugs.

We proceeded to analyze whether the relationships among the three measures of sleep problems and substance use were mediated by attention problems, anxiety/depression, or aggression. Holding parental alcoholism and age constant, we systematically tested whether measures of sleep problems predicted behavioral problems in late childhood. Because of the possible nonlinear relationship between the two, we analyzed behavioral problems both as continuous problems and dichotomous variables by using the 75th percentile scores as the cutoff. As seen in Table 4, sleep measures were significantly related to some of the continuous measures of behavioral problems. However, there was no significant relationship between any of sleep measures and the dichotomous measures of behavioral problems. Therefore, we focused only on the analyses using behavioral problems as continuous variables. The composite index of sleep problems and overtiredness had a significantly positive relationship with attention problems and anxiety. However, these two measures did not predict aggression. Moreover, having trouble sleeping had no significant relationship with any of the behavioral problems.

Next we examined how the relationship between early childhood sleep problems and adolescent substance use changed in the presence of behavioral problems in late childhood. Because having trouble sleeping was not related to any of the behavioral problems, its effects on substance use were not mediated by these problems. Similarly, because overtiredness and the composite index of sleep problems did not predict aggression, their effects on substance use could not have been mediated by aggression. Thus, it is not necessary to continue the mediator analyses with the previously described variables. However, we opted to leave trouble sleeping and aggression in the analyses to find out whether the relationships among the sleep measures and substance use outcomes reported in Table 3 varied in the presence of any behavioral problems.

Table 5 showed the relationship among early childhood sleep problems, late childhood behavioral problems, and adolescent substance use. We included only the substance use variables that were significantly predicted by the sleep measures. For instance, there was no relationship between any of sleep measures and onset of drunkenness, so we did not include onset of drunkenness in this analysis. As shown in Table 5, attention problems and anxiety/depression in late childhood did not significantly predict the onset of substance use in the presence of our sleep measures. Attention problems and anxiety/depression did not seem to mediate the relationship between sleep problems and onset of substance use. Moreover, although aggression significantly predicted early onset of regular cigarette use, it did not vary the relationship between sleep problems and cigarette use. Before including aggression in the model, the odds ratio of sleep problems was $2.27(p<0.05)$. When aggression was included, the odds ratio of sleep problems remained virtually unchanged (odds ratio, 2.22; $p<0.05$ ). 
Table 2. Number and Percentages of Respondents Having Childhood Sleep Problems and Onset of Adolescent Alcohol and Other Drug Use

\begin{tabular}{|c|c|c|c|c|c|c|}
\hline & \multicolumn{2}{|c|}{ Sleep Problems } & \multicolumn{2}{|c|}{ Trouble Sleeping } & \multicolumn{2}{|c|}{ Overtired } \\
\hline & No & Yes & No & Yes & No & Yes \\
\hline \multicolumn{7}{|c|}{ Onset of drinking } \\
\hline \multirow{2}{*}{ No } & 127 & 48 & 159 & 16 & 134 & 41 \\
\hline & $72.6 \%$ & $27.4 \%$ & $90.9 \%$ & $9.1 \%$ & $76.6 \%$ & $23.4 \%$ \\
\hline \multirow[t]{2}{*}{ Yes } & 44 & 38 & 66 & 16 & 52 & 30 \\
\hline & $53.7 \%$ & $46.3 \%$ & $80.5 \%$ & $19.5 \%$ & $63.4 \%$ & $36.6 \%$ \\
\hline \multicolumn{7}{|c|}{ Onset of drunkenness } \\
\hline \multirow[t]{2}{*}{ No } & 153 & 71 & 197 & 27 & 166 & 58 \\
\hline & $68.3 \%$ & $31.7 \%$ & $87.9 \%$ & $12.1 \%$ & $74.1 \%$ & $25.9 \%$ \\
\hline \multirow[t]{2}{*}{ Yes } & 18 & 15 & 28 & 5 & 20 & 13 \\
\hline & $54.5 \%$ & $45.5 \%$ & $84.8 \%$ & $15.2 \%$ & $60.6 \%$ & $39.4 \%$ \\
\hline \multicolumn{7}{|c|}{ Onset of occasional or regular cigarette use } \\
\hline \multirow[t]{2}{*}{ No } & 156 & 70 & 200 & 26 & 167 & 59 \\
\hline & $69.0 \%$ & $31.0 \%$ & $88.5 \%$ & $11.5 \%$ & $73.9 \%$ & $26.1 \%$ \\
\hline \multirow[t]{2}{*}{ Yes } & 15 & 16 & 25 & 6 & 19 & 12 \\
\hline & $48.4 \%$ & $51.6 \%$ & $80.6 \%$ & $19.4 \%$ & $61.3 \%$ & $38.7 \%$ \\
\hline \multicolumn{7}{|c|}{ Onset of marijuana use } \\
\hline \multirow[t]{2}{*}{ No } & 155 & 68 & 198 & 25 & 167 & 56 \\
\hline & $69.5 \%$ & $30.5 \%$ & $88.8 \%$ & $11.2 \%$ & $74.9 \%$ & $25.1 \%$ \\
\hline \multirow[t]{2}{*}{ Yes } & 15 & 18 & 26 & 7 & 18 & 15 \\
\hline & $45.5 \%$ & $54.5 \%$ & $78.8 \%$ & $21.2 \%$ & $54.5 \%$ & $45.5 \%$ \\
\hline \multicolumn{7}{|c|}{ Onset of illicit drug use } \\
\hline \multirow[t]{2}{*}{ No } & 149 & 64 & 189 & 24 & 160 & 53 \\
\hline & $70.0 \%$ & $30.0 \%$ & $88.7 \%$ & $11.3 \%$ & $75.1 \%$ & $24.9 \%$ \\
\hline \multirow[t]{2}{*}{ Yes } & 22 & 22 & 36 & 8 & 26 & 18 \\
\hline & $50.0 \%$ & $50.0 \%$ & $81.8 \%$ & $18.2 \%$ & $59.1 \%$ & $40.9 \%$ \\
\hline
\end{tabular}

\section{DISCUSSION}

Early childhood sleep problems seem to be a robust marker for substance use in adolescence. Sleep problems significantly increased the likelihood of early onset of alcohol, marijuana, and other drug use. Sleep problems also increased the risk for early onset of occasional or regular cigarette use. The relationship between sleep problems and onset of substance use was weaker when individual sleep items instead of the composite indicator were examined in the logistic regression analyses. This might mean that different sleep problems affected the risk of substance use differently. This could also be related to the low statistical power of detecting significant effects for the sleep item "having trouble sleeping"- only $12.5 \%$ of the participants had this problem in early childhood.

Other known precursors/predictors of the early use of alcohol and other drugs - in particular, attention problems, anxiety/depression, and aggression-in late childhood did not seem to attenuate the relationship among sleep measures and substance use. It might be of some concern that these T3 measures do not present substance use outcomes, given the substantial literature that at least links externalizing problems to these adolescent behaviors (e.g., Caspi et al., 1996; Chassin et al., 1999; Donovan and Jessor, 1985). Other data from our group, reported in Zucker et al. (2003), stress that T3 is developmentally a time when individual differences in these behaviors are reduced (i.e., the variability is substantially lower at the 9- to 11-year age range). This is in contrast to the observed dispersion in early childhood and again in adolescence. Our work indicated that at both of these time periods, the effects of externalizing and internalizing problems on substance use outcomes were significant (Mayzer et al., 2001; Wong et al., 2003).

This work suggests that sleep difficulties early in the life of a child are a marker of an independent contributor to early substance involvement. Given that early alcohol involvement has repeatedly been shown to be a marker of substantially greater risk for alcohol dependence in adulthood, as well as a host of adolescent problems, including injuries, violence, and drunk driving (Gruber et al., 1996), the fact that such a developmentally early and easily obtainable measure is predictive has potentially very significant implications as an early risk identifier. Information about sleep problems is obtainable both at the pediatrician's office and in early health screens by the school nurse. Because of its minimal cost, this indicator has the potential for widespread application.

Our findings provide additional evidence, albeit in a new domain, that the markers of adolescent alcohol and other drug use are detectable very early in the life course. This is far earlier than the dominant causal paradigms of later childhood and early adolescence embraced by the field. Evidence reviewed in an NIAAA report to congress (NIAAA, 2000) summarizes that early externalizing problems (behavioral undercontrol and aggressiveness) are a highly robust preschool indicator of a life course culminating in high rates of alcohol problems and alcohol dependence some 15 to 20 years later. Our results suggest that another pathway (i.e., sleep to drug onset) for these outcomes can be identified. Given the importance of alcohol problems as a public health problem, the potential availability of another, easily assessed marker of very early risk 
Table 3. The Effects of Childhood Sleep Problems on Adolescent Alcohol and Other Drug Use

\begin{tabular}{|c|c|c|c|}
\hline & Wald $\chi^{2}$ & Odds Ratio & $95 \% \mathrm{Cl}$ \\
\hline \multicolumn{4}{|l|}{ Onset of drinking } \\
\hline Parental alcoholism & 10.34 & $2.65^{\star \star}$ & $1.46-4.80$ \\
\hline Age & 4.42 & $1.55^{\star}$ & $1.03-2.33$ \\
\hline Sleep problems & 7.96 & $2.25^{\star \star}$ & $1.28-3.96$ \\
\hline Parental alcoholism & 10.52 & $2.66^{\star \star}$ & $1.47-4.81$ \\
\hline Age & 4.66 & $1.57^{\star}$ & $1.04-2.36$ \\
\hline Trouble sleeping & 4.58 & $2.32^{\star}$ & $1.07-5.03$ \\
\hline Parental alcoholism & 10.16 & $2.61^{\star \star}$ & $1.45-4.70$ \\
\hline Age & 4.85 & $1.58^{*}$ & $1.05-2.37$ \\
\hline Overtired & 4.14 & $1.84^{*}$ & $1.02-3.32$ \\
\hline \multicolumn{4}{|l|}{ Onset of drunkenness } \\
\hline Parental alcoholism & 4.17 & $2.44^{\star}$ & $1.04-5.72$ \\
\hline Age & 6.36 & $2.57^{*}$ & $1.23-5.36$ \\
\hline Sleep problems & 1.81 & 1.69 & $0.79-3.60$ \\
\hline Parental alcoholism & 4.4 & $2.49^{\star}$ & $1.06-5.83$ \\
\hline Age & 6.56 & $2.62^{\star}$ & $1.25-5.46$ \\
\hline Trouble sleeping & 0.12 & 1.21 & $0.42-3.47$ \\
\hline Parental alcoholism & 4.01 & $2.40^{\star}$ & $1.02-5.64$ \\
\hline Age & 6.53 & $2.60^{\star}$ & $1.25-5.40$ \\
\hline Overtired & 2.09 & 1.78 & $0.82-3.90$ \\
\hline \multicolumn{4}{|c|}{$\begin{array}{l}\text { Onset of occasional or regular } \\
\text { cigarette use }\end{array}$} \\
\hline Parental alcoholism & 3.00 & 2.15 & $0.91-5.09$ \\
\hline Age & 4.60 & $2.17^{\star}$ & $1.07-4.40$ \\
\hline Sleep problems & 4.31 & $2.27^{*}$ & $1.05-4.91$ \\
\hline Parental alcoholism & 3.26 & 2.21 & $0.93-5.20$ \\
\hline Age & 4.83 & $2.21^{\star}$ & $1.09-4.49$ \\
\hline Trouble sleeping & 1.18 & 1.74 & $0.64-4.73$ \\
\hline Parental alcoholism & 3.00 & 2.14 & $0.91-5.05$ \\
\hline Age & 4.85 & $2.21^{*}$ & $1.09-4.46$ \\
\hline Overtired & 1.76 & 1.72 & $0.77-3.81$ \\
\hline \multicolumn{4}{|l|}{ Onset of marijuana use } \\
\hline Parental alcoholism & 4.22 & $2.48^{\star}$ & $1.04-5.91$ \\
\hline Age & 8.17 & $3.26^{\star \star}$ & $1.45-7.31$ \\
\hline Sleep problems & 6.04 & $2.62^{*}$ & $1.22-5.63$ \\
\hline Parental alcoholism & 4.61 & $2.56^{*}$ & $1.09-6.06$ \\
\hline Age & 8.42 & $3.33^{* \star}$ & $1.48-7.50$ \\
\hline Trouble sleeping & 2.05 & 2.03 & $0.77-5.35$ \\
\hline Parental alcoholism & 4.03 & $2.43^{*}$ & $1.02-5.77$ \\
\hline Age & 8.47 & $3.30^{\star \star}$ & $1.48-7.37$ \\
\hline Overtired & 4.97 & $2.43^{\star}$ & $1.11-5.28$ \\
\hline \multicolumn{4}{|l|}{ Onset of illicit drug use } \\
\hline Parental alcoholism & 6.83 & $2.82^{\star \star}$ & $1.30-6.13$ \\
\hline Age & 8.08 & $2.54^{\star \star}$ & $1.34-4.81$ \\
\hline Sleep problems & 5.34 & $2.24^{\star}$ & $1.13-4.44$ \\
\hline Parental alcoholism & 7.21 & $2.88^{\star \star}$ & $1.33-6.22$ \\
\hline Age & 8.4 & $2.57^{\star \star}$ & $1.36-4.88$ \\
\hline Trouble sleeping & 1.17 & 1.65 & $0.67-4.10$ \\
\hline Parental alcoholism & 6.64 & $2.77^{\star}$ & $1.28-6.02$ \\
\hline Age & 8.41 & $2.57^{\star \star}$ & $1.36-4.86$ \\
\hline Overtired & 3.88 & $2.03^{*}$ & $1.00-4.11$ \\
\hline
\end{tabular}

${ }^{\star} p<.05 ;{ }^{* \star} p<.01 ;{ }^{* \star \star} p<.001$.

represents an important new finding and a potentially important public health contribution.

It needs to be underscored, however, that the existence of these relationships still tells us nothing about what underlying mechanisms produce the problem outcome. Our mediational analyses indicate that the pathway of effect seems not to be through the already demonstrated pathways of behavioral undercontrol and inattention. However, our analyses are not informative about the brain mecha- nisms contributing to the sleep disturbances, nor do they tell us how such disturbances ultimately drive the earlier onset of alcohol and other drug use. Clearly, much more work needs to be performed for us to understand the epigenesis of the relationship and the neurocognitive processes that drive it.

Given the consistency of sleep problems in predicting the onset of a number of different classes of drugs, it would seem that whatever mechanism is involved, it is not drug specific. Whether the mechanism involves a common genetic vulnerability (Kendler et al., 2003; Tsuang et al., 1998) that also shows itself in a physiologic regulatory deficit such as sleep problems or one that creates a cognitive vulnerability leading to poor peer selection and higher drug exposure (Donovan and Jessor, 1985) remains to be established. A self-medication mechanism that involves using alcohol to aid sleep may also be possible (Brower, 2001). More work needs to be performed to understand the mechanisms that are operating here.

This study has several limitations. First, only mothers' ratings of sleep problems were used. Their ratings perhaps reflect disturbances in the mother/child relationship that are connected to early infant and toddler sleep patterns. These disturbances may be shaped by both the characteristics of the mother (e.g., her own alcohol problems, depression, or lack of experience) and those of her toddler. At the same time, it should be noted that we controlled for the effect of parental alcoholism and still observed a positive relationship between sleep problems and substance use. Additionally, in subsequent analyses not presented here, we also controlled for maternal depression, as measured by the Hamilton Depression Inventory (Hamilton, 1960). The relationship between childhood sleep problems and substance use outcomes did not change in the presence of maternal depression. $\dagger$ Nevertheless, the effects of other parental characteristics on the outcomes need to be controlled for in future studies. Second, our analyses did not include any information before ages 3 to 5 . Data pertaining to prenatal development and sleep/wakefulness information in the first 3 years of life are necessary for a thorough analysis of sleep problems in early childhood. Third, the

$\dagger$ We tested whether higher levels of maternal depression might adversely affect maternal ratings of sleep problems. Maternal depression was measured by the Hamilton Depression Inventory scores (Hamilton, 1960) in the last 3 years when children were 3 to 5 years old. Using the 75th percentile as the cutoff point, mothers were separated into two groups based on their Hamilton Depression Inventory scores. Preliminary analyses showed that there was no significant relationship between these scores and mother ratings of sleep problems [two-item composite; $\left.\chi^{2}(1)=2.39\right]$. Subsequent logistic regression analyses using parental alcoholism, maternal depression, age of respondents at T4, and sleep problems predicting the onset of substance use showed that maternal depression did not significantly predict any outcomes. Moreover, including maternal depression in the model did not alter the relationship between sleep problems and any substance use variables. Because including an additional independent variable has the potential to decrease statistical power to detect significant effects from other independent variables, we decided to exclude maternal depression as a predictor. 
Table 4. The effects of early childhood sleep problems on attention problems, anxiety/depression, aggression in late childhood

\begin{tabular}{|c|c|c|c|c|c|}
\hline \multirow{2}{*}{$\begin{array}{l}\text { Behavioral } \\
\text { Problems }\end{array}$} & \multicolumn{2}{|c|}{ As Continuous Variables } & \multicolumn{3}{|c|}{ As Dichotomous Variables (75th Percentile Split) } \\
\hline & $\beta$ & $t$ & Wald $\chi^{2}$ & Odds Ratio & $95 \% \mathrm{Cl}$ \\
\hline \multicolumn{6}{|l|}{ Attention problems } \\
\hline Sleep problems & 0.16 & $2.57^{\star}$ & 2.48 & 1.62 & $0.88-2.96$ \\
\hline Trouble sleeping & 0.11 & 1.73 & 0.45 & 1.33 & $0.58-3.07$ \\
\hline Overtired & 0.14 & $2.31^{*}$ & 3.49 & 1.81 & $0.97-3.38$ \\
\hline \multicolumn{6}{|l|}{ Anxiety/depression } \\
\hline Sleep problems & 0.14 & $2.31^{*}$ & 0.63 & 1.31 & $0.68-2.52$ \\
\hline Trouble sleeping & 0.08 & 1.36 & 0.16 & 0.82 & $0.3-2.25$ \\
\hline Overtired & 0.16 & $2.58^{\star}$ & 3.48 & 1.89 & $0.97-3.69$ \\
\hline \multicolumn{6}{|l|}{ Aggression } \\
\hline Sleep problems & 0.11 & 1.73 & 1.05 & 1.38 & $0.75-2.55$ \\
\hline Trouble sleeping & 0.05 & 0.81 & 0.21 & 1.22 & $0.52-2.90$ \\
\hline Overtired & 0.1 & 1.59 & 1.49 & 1.49 & $0.79-2.82$ \\
\hline
\end{tabular}

All behavioral problems were analyzed as both continuous variables and dichotomous variables. All analyses controlled for the effects of parental alcoholism and participants' age. For ease of presentation, they are not listed here.

${ }^{*} p<.05 ;{ }^{* *} p<.01 ;{ }^{* \star *} p<.001$.

Table 5. Relationship Among Sleep Problems, Attention Problems, Anxiety/Depression, Aggression, and Onset of Alcohol and Other Drug Use

\begin{tabular}{|c|c|c|c|c|c|c|c|c|c|c|c|}
\hline & Wald $\chi^{2}$ & O.R. & $95 \% \mathrm{Cl}$ & & Wald $\chi^{2}$ & O.R. & $95 \% \mathrm{Cl}$ & & Wald $\chi^{2}$ & O.R. & $95 \% \mathrm{Cl}$ \\
\hline \multicolumn{12}{|c|}{ Onset of drinking } \\
\hline PA & 10.35 & $2.65^{\star \star}$ & $1.46-4.80$ & PA & 10.23 & $2.64^{\star \star}$ & $1.46-4.78$ & PA & 10.38 & $2.66^{\star \star}$ & $1.47-4.80$ \\
\hline Age & 4.43 & $1.55^{\star}$ & $1.03-2.34$ & Age & 4.43 & $1.55^{\star}$ & $1.03-2.33$ & Age & 4.37 & $1.55^{\star}$ & $1.03-2.33$ \\
\hline $\mathrm{SP}$ & 7.96 & $2.25^{\star \star}$ & $1.28-3.96$ & $\mathrm{SP}$ & 8.02 & $2.26^{\star \star}$ & $1.29-3.98$ & $\mathrm{SP}$ & 7.80 & $2.24^{\star \star}$ & $1.27-3.94$ \\
\hline \multirow[t]{2}{*}{ Attention } & 0.00 & 1.00 & $0.89-1.12$ & Anxiety & 0.46 & 0.96 & $0.86-1.07$ & Aggression & 0.52 & 1.02 & $0.97-1.08$ \\
\hline & $(0.02$ & 0.96 & $0.50-1.84)$ & & $(0.12$ & 0.88 & $0.43-1.81)$ & & $(0.27$ & 1.19 & $1.03-2.33)$ \\
\hline PA & 10.51 & $2.66^{\star \star}$ & $1.47-4.81$ & PA & 10.46 & $2.66^{\star \star}$ & $1.47-4.80$ & PA & 10.54 & $2.67^{\star \star}$ & $1.48-4.82$ \\
\hline Age & 4.62 & $1.57^{\star}$ & $1.04-2.36$ & Age & 4.68 & $1.57^{\star}$ & $1.04-2.36$ & Age & 4.56 & $1.56^{\star}$ & $1.04-2.35$ \\
\hline TS & 4.57 & $2.32^{*}$ & $1.07-5.03$ & TS & 4.55 & $2.32^{*}$ & $1.07-5.02$ & TS & 4.50 & $2.31^{*}$ & $1.07-5.00$ \\
\hline \multirow[t]{2}{*}{ Attention } & 0.07 & 1.02 & $0.91-1.14$ & Anxiety & 0.21 & 0.98 & $0.88-1.09$ & Aggression & 0.78 & 1.02 & $0.97-1.08$ \\
\hline & $(0.00$ & 1.01 & $0.53-1.93)$ & & $(0.04$ & 0.93 & $0.46-1.91)$ & & $(0.36$ & 1.22 & $0.64-2.34)$ \\
\hline PA & 10.17 & $2.61^{\star \star}$ & $1.45-4.70$ & PA & 10.00 & $2.60^{\star \star}$ & $1.44-4.67$ & PA & 10.21 & $2.62^{\star \star}$ & $1.45-4.72$ \\
\hline Age & 4.86 & $1.58^{\star}$ & $1.05-2.37$ & Age & 4.88 & $1.58^{\star}$ & $1.05-2.37$ & Age & 4.78 & $1.58^{\star}$ & $1.05-2.36$ \\
\hline OT & 4.13 & $1.85^{\star}$ & $1.02-3.34$ & OT & 4.29 & $1.84^{\star}$ & $1.03-3.38$ & OT & 3.99 & $1.83^{\star}$ & $1.01-3.29$ \\
\hline \multirow[t]{2}{*}{ Attention } & 0.04 & 1.01 & $0.90-1.13$ & Anxiety & 0.35 & 0.97 & $0.87-1.08$ & Aggression & 0.67 & 1.02 & $0.97-1.08$ \\
\hline & $(0.01$ & 0.97 & $0.51-1.85)$ & & $(0.20$ & 0.85 & $0.41-1.70)$ & & $(0.29$ & 1.20 & $0.62-2.29)$ \\
\hline \multicolumn{12}{|c|}{ Onset of occasional or regular cigarette use } \\
\hline PA & 2.98 & 2.14 & $0.90-5.08$ & PA & 2.92 & 2.13 & $0.89-5.05$ & PA & 3.04 & 2.16 & $0.91-5.14$ \\
\hline Age & 4.51 & $2.15^{\star}$ & $1.06-4.37$ & Age & 4.64 & $2.17^{\star}$ & $1.07-4.39$ & Age & 4.52 & $2.17^{\star}$ & $1.06-4.43$ \\
\hline SP & 4.19 & $2.24^{\star}$ & $1.04-4.87$ & SP & 4.48 & $2.31^{*}$ & $1.06-5.02$ & SP & 4.07 & $2.22^{\star}$ & $1.02-4.83$ \\
\hline \multirow[t]{2}{*}{ Attention } & 0.52 & 1.06 & $0.91-1.23$ & Anxiety & 0.50 & 0.94 & $0.80-1.11$ & Aggression & 4.07 & $1.08^{\star}$ & $1.00-1.15$ \\
\hline & $(0.24$ & 1.24 & $0.53-2.94)$ & & $(0.76$ & 0.61 & $0.20-1.88)$ & & $(1.81$ & 1.79 & $0.77-4.17)$ \\
\hline \multicolumn{12}{|c|}{ Onset of marijuana use } \\
\hline PA & 4.21 & $2.48^{\star}$ & $1.04-5.90$ & PA & 4.13 & $2.47^{*}$ & $1.03-5.89$ & PA & 4.23 & $2.49^{*}$ & $1.04-5.92$ \\
\hline Age & 8.12 & $3.25^{\star \star}$ & $1.44-7.30$ & Age & 8.23 & $3.25^{\star \star}$ & $1.45-7.27$ & Age & 8.10 & $3.26^{\star \star}$ & $1.45-7.37$ \\
\hline $\mathrm{SP}$ & 5.99 & $2.61^{\star}$ & $1.21-5.62$ & $\mathrm{SP}$ & 6.29 & $2.68^{\star}$ & $1.24-5.80$ & SP & 5.90 & $2.59^{\star}$ & $1.20-5.59$ \\
\hline \multirow[t]{2}{*}{ Attention } & 0.13 & 0.97 & $0.83-1.14$ & Anxiety & 0.79 & 0.93 & $0.78-1.10$ & Aggression & 0.10 & 1.01 & $0.94-1.09$ \\
\hline & $(0.03$ & 1.08 & $0.46-2.58)$ & & $(1.11$ & 0.54 & $0.17-1.70)$ & & $(0.39$ & 1.32 & $0.55-3.17)$ \\
\hline PA & 4.01 & $2.42^{*}$ & $1.02-5.76$ & PA & 3.87 & $3.39^{\star}$ & $1.00-5.71$ & PA & 4.06 & $2.44^{*}$ & $1.03-5.80$ \\
\hline Age & 8.42 & $3.29^{\star \star}$ & $1.47-7.37$ & Age & 8.57 & $3.30^{\star \star}$ & $1.48-7.33$ & Age & 8.40 & $3.31^{\star *}$ & $1.47-7.43$ \\
\hline OT & 4.90 & $2.42^{\star}$ & $1.11-5.27$ & OT & 5.58 & $2.59^{\star}$ & $1.18-5.7$ & OT & 4.83 & $2.40^{\star}$ & $1.10-5.23$ \\
\hline \multirow[t]{2}{*}{ Attention } & 0.08 & 0.98 & $0.84-1.14$ & Anxiety & 0.79 & 0.93 & $0.79-1.09$ & Aggression & 0.16 & 1.02 & $0.95-1.09$ \\
\hline & $(0.02$ & 1.07 & $0.45-2.54)$ & & $(1.40$ & 0.50 & $0.16-1.58)$ & & $(0.40$ & 1.33 & $0.55-3.17)$ \\
\hline \multicolumn{12}{|c|}{ Onset of illicit drug use } \\
\hline PA & 6.80 & $2.81^{\star \star}$ & $1.29-6.12$ & PA & 6.74 & $2.8^{\star \star}$ & $1.29-6.10$ & PA & 6.86 & $2.83^{\star \star}$ & $1.30-6.16$ \\
\hline Age & 7.99 & $2.52^{\star \star}$ & $1.33-4.80$ & Age & 8.11 & $2.53^{\star \star}$ & $1.34-4.80$ & Age & 8.00 & $2.53^{\star \star}$ & $1.33-4.83$ \\
\hline $\mathrm{SP}$ & 5.25 & $2.23^{\star}$ & $1.12-4.42$ & $\mathrm{SP}$ & 5.42 & $2.26^{\star}$ & $1.14-4.48$ & $\mathrm{SP}$ & 5.16 & $2.21^{*}$ & $1.12-4.40$ \\
\hline \multirow[t]{2}{*}{ Attention } & 0.28 & 0.96 & $0.84-1.11$ & Anxiety & 0.06 & 0.98 & $0.86-1.13$ & Aggression & 0.08 & 1.01 & $0.95-1.08$ \\
\hline & $(0.09$ & 1.12 & $0.52-2.44)$ & & $(0.22$ & 0.80 & $0.32-2.02)$ & & $(0.64$ & 1.38 & $0.63-3.00)$ \\
\hline PA & 6.61 & $2.77^{\star \star}$ & $1.27-6.00$ & PA & 6.51 & $2.75^{\star}$ & $1.26-5.97$ & PA & 6.70 & $2.79^{* *}$ & $1.28-6.06$ \\
\hline Age & 8.32 & $2.56^{\star \star}$ & $1.35-4.85$ & Age & 8.46 & $2.57^{\star \star}$ & $1.36-4.85$ & Age & 8.31 & $2.57^{\star \star}$ & $1.35-4.88$ \\
\hline ОT & 3.78 & 2.02 & $0.99-4.09$ & OT & 4.10 & $2.08^{\star}$ & $1.02-4.24$ & OT & 3.72 & 2.00 & $0.99-4.06$ \\
\hline \multirow[t]{2}{*}{ Attention } & 0.19 & 0.97 & $0.84-1.11$ & Anxiety & 0.06 & 0.98 & $0.86-1.12$ & Aggression & 0.12 & 1.01 & $0.95-1.08$ \\
\hline & $(0.08$ & 1.11 & $0.52-2.41)$ & & $(0.34$ & 0.76 & $0.30-1.91)$ & & $(0.65$ & 1.38 & $0.63-3.00)$ \\
\hline
\end{tabular}

OR, odds ratio; PA, parental alcoholism; SP, sleep problems; TS, trouble sleeping; OT, overtired. Numbers in parentheses are parameter estimates from analyzing attention problems, anxiety, and aggression as discrete variables. For ease of presentation, parameter estimates for PA, age, and sleep problems in those models were not presented. These analyses were performed only if any of the three sleep measures (i.e., SP, TS, or OT) significantly predicted the outcomes.

${ }^{\star} p<.05 ;{ }^{* \star} p<.01 ;{ }^{\star \star *} p<.001$. 
sample contained only boys; thus, no examination of potential gender differences in the relationship between sleep problems and alcohol use was possible. We plan to include girls' data as soon as they become available. Fourth, as noted previously, our sample of families was deliberately selected so that offspring were at the high end of the continuum of risk for alcohol use disorder. These findings need to be replicated in other samples at high risk for drug abuse and in general population samples. Fifth, our measures of sleep problems were limited to two mother-rated items that do not fully capture the spectrum of childhood sleep problems. Furthermore, overtiredness can be caused by factors other than sleep problems, such as inadequate nutrition. Studies using polysomnographic measures in addition to sleep questionnaires are needed.

Despite these limitations, these findings offer an intriguing new hypothesis about one of the causal factors involved in early alcohol and other drug use. The sleep problem measure is one that falls in the general category of indicators of instability in biological rhythm, a domain that has previously been linked to the etiology of depression and has also been causally linked to social dysregulation (Ehlers et al., 1988). Furthermore, as we noted previously, the prospective relationship observed here has also been documented cross-sectionally in other studies of adolescents (Johnson and Breslau, 2001; Tynjala et al., 1997; Vignau et al., 1997). That is, sleep disturbances as reported by adolescents have been positively correlated with the presence of alcohol and other drug problems, suggesting that the relationship observed in this study is a developmentally robust one and that parent observer bias effects may be relatively minimal. Finally, it is interesting to note that sleep disturbances, particularly insomnia, are predictive of the onset of recurring alcohol use among adult alcoholics in remission (Brower et al., 2001); i.e., this dysregulation indicator is also a marker of the re-emergence of alcohol problems in adulthood. Taken altogether, these studies provide a chain of evidence linking sleep disturbances to alcohol problems across a large segment of the life span. Given the centrality of sleep in the chronobiology of the human organism and the public health importance of finding early markers of risk of alcohol use disorder that may also be relatively easily remedied, it is important that this work be replicated and that the mechanisms underlying the association be identified.

\section{REFERENCES}

Achenbach T (1991) Manual for the Child Behavior Checklist/4-18 and 1991 Profile. University of Vermont Department of Psychiatry, Burlington.

Achenbach T, Edelbrock C (1983) Manual for the Child Behavior Checklist and Revised Child Behavior Profile. University Associates in Psychiatry, Burlington, VT.

American Psychiatric Association (2000) DSM-IV-TR Diagnostic and Statistical Manual of Mental Disorders. 4th ed., text rev. American Psychiatric Association, Washington, DC.
American Sleep Disorders Association (1997) International Classification of Sleep Disorders, Revised: Diagnostic and Coding Manual. American Sleep Disorders Association, Rochester, MN.

Baron RM, Kenny DA (1986) The moderator-mediator variable distinction in social psychological research: conceptual, strategic, and statistical considerations. J Pers Soc Psychol 51:1173-1182.

Beck AT, Steer RA, Garbin M (1988) Psychometric properties of the Beck Depression Inventory. Clin Psychol Rev 8:77-100.

Breslau N, Roth T, Rosenthal L, Andreski P (1996) Sleep disturbance and psychiatric disorders: a longitudinal epidemiological study of young adults. Biol Psychiatry 39:411-418.

Brower KJ (2001) Alcohol's effects on sleep in alcoholics. Alcohol Res Health 25:110-125.

Brower KJ, Aldrich MS, Hall JM (1998) Polysomnographic and subjective sleep predictors of alcoholic relapse. Alcohol Clin Exp Res 22:18641871.

Brower KJ, Aldrich MS, Robinson EAR, Zucker RA, Greden JF (2001) Insomnia, self-medication and relapse to alcoholism. Am J Psychiatry 158:399-404.

Carskadon MA, Vieira C, Acebo C (1993) Association between puberty and delayed phase preference. Sleep 16:258-262.

Caspi A, Moffit TE, Newman DL, Silva PA (1996) Behavioral observations at age 3 years predict adult psychiatric disorders: longitudinal evidence from a birth cohort. Arch Gen Psychiatry 53:1033-1039.

Chang PP, Ford DE, Mead LA, Cooper-Patrick L, Klag MJ (1997) Insomnia in young men and subsequent depression: the Johns Hopkins Precursors Study. Am J Epidemiol 146:105-114.

Chassin L, Pitts SC, DeLucia C, Todd M (1999) A longitudinal study of children of alcoholics: predicting young adult substance use disorders, anxiety, and depression. J Abnorm Psychol 108:106-119.

Chervin RD, Dillon JE, Archbold KH, Ruzicka DL (2003) Conduct problems and symptoms of sleep disorders in children. Am Acad Child Adolesc Psychiatry 42:201-208.

Chervin RD, Dillon JE, Bassetti C, Ganoczy DA, Pituch KJ (1997) Symptoms of sleep disorders, inattention, and hyperactivity in children. Sleep 20:1185-1192.

Cooper ML, Russell M, Skinner JB, Frone MR (1992) Stress and alcohol use: moderating effects of gender, coping, and alcohol expectancies. J Abnorm Psychol 10:139-152.

Dahl RE (1996) The regulation of sleep and arousal: development and psychopathology. Dev Psychopathol 8:3-27.

Dahl RE, Carskadon MA (1995) Sleep and its disorders in adolescence, in Principles and Practices of Sleep Medicine in the Child. 2nd ed, pp 19-27. WB Saunders.

Donovan JE, Jessor R (1985) Structure of problem behavior in adolescence and young adulthood. J Consult Clin Psychol 53:890-904.

Eaton WW, Badawi M, Melton B (1995) Prodromes and precursors: epidemiologic data for primary prevention of disorders with slow onset. Am J Psychiatry 152:967-972.

Ehlers CL, Frank E, Kupfer DJ (1988) Social zeitgebers and biological rhythms: a unified approach to understanding the etiology of depression. Arch Gen Psychiatry 45:948-952.

Fitzgerald HE, Sullivan LA, Ham HP, Zucker RA, Bruckel S, Schneider AM (1993) Predictors of behavioral problems in three-year-old sons of alcoholics: early evidence for onset of risk. Child Dev 64:110-123.

Fitzgerald HE, Zucker RA, Yang H-Y (1995) Developmental systems theory and alcoholism: analyzing patterns of variation in high risk families. Psychol Addict Behav 9:8-22.

Ford DE, Kamerow DB (1989) Epidemiologic study of sleep disturbance and psychiatric disorders. JAMA 262:1479-1484.

Foster JH, Marshall EJ, Peters TJ (1998) Predictors of relapse to heavy drinking in alcohol dependent subjects following alcohol detoxification: the role of quality of life measures, ethnicity, social class, cigarette and drug use. Addict Biol 3:333-343.

Foster JH, Peters TJ (1999) Impaired sleep in alcohol misusers and dependent alcoholics and the impact upon outcome. Alcohol Clin Exp Res 23:1044-1051. 
Graham JW, Hofer SM (2000) Multiple imputation in multivariate research, in Modeling Longitudinal and Multilevel Data: Practical Issues, Applied Approaches, and Specific Examples (Little TD, Schnabel KU, Baumert J eds), pp 201-218. Erlbaum, Mahwah, NJ.

Grant BF, Dawson DA (1997) Age at onset of alcohol use and its association with DSM-IV alcohol abuse and dependence: results from the National Longitudinal Alcohol Epidemiological Survey. J Subst Abuse 10:59-73.

Gruber E, DiClemente RJ, Anderson MM, Lodico M (1996) Early drinking onset and its association with alcohol use and problem behavior in late adolescence. Prev Med 25:293-300.

Guilleminault C, Korobkin R, Winkle R (1981) A review of 50 children with obstructive sleep apnea syndrome. Lung 159:275-287.

Guilleminault C, Winkle R, Korobkin R, Simmons B (1982) Children and nocturnal snoring: evaluation of the effects of sleep related respiratory resistive load and daytime functioning. Eur J Pediatr 139:165-171.

Hamilton M (1960) A rating scale for depression. J Neurol Neurosurg Psychiatry 23:56-62.

Hamilton M (1969) Standardised assessment and recording of depressive symptoms. Psychiatr Neurol Neurochir 72:201-205.

Helzer JE, Burnam A, McEvoy LT (1991) Alcohol Abuse and Dependence. Free Press, New York.

Hussong AM, Hicks RE, Levy SA, Curran PJ (2001) Specifying the relations between affect and heavy alcohol use among young adults. J Abnorm Psychol 110:449-461.

Johnson EO, Breslau N (2001) Sleep problems and substance use in adolescence. Drug Alcohol Depend 64:1-7.

Johnson EO, Roehrs T, Roth T, Breslau N (1998) Epidemiology of alcohol and medication as aids to sleep in early adulthood. Sleep 21:178-186.

Johnston LD, O'Malley PM, Bachman JG (2002) Monitoring the Future National Results on Adolescent Drug Use: Overview of Key Findings, 2001. National Institute on Drug Abuse, Bethesda, MD.

Kendler KS, Jacobson KC, Prescott CA, Neale MC (2003) Specificity of genetic and environmental risk factors for use and abuse/dependence of cannabis, cocaine, hallucinogens, sedatives, stimulants, and opiates in male twins. Am J Psychiatry 160:687-695.

Landolt HP, Gillin JC (2001) Sleep abnormalities during abstinence in alcohol-dependent patients. Aetiology and management. CNS Drugs 15:413-425.

Little RJA, Rubin DB (1987) Statistical Analysis With Missing Data. Wiley, New York.

Mayzer R, Wong MM, Puttler LI, Fitzgerald HE, Zucker RA (2001) Onset of alcohol use: profiling adolescents characterized as "early drinkers." Presented at the Annual Meeting of the American Society of Criminology, Atlanta, GA.

National Institute on Alcohol Abuse and Alcoholism (1998) Alcohol Alert No. 41: Alcohol and Sleep. National Institute on Alcohol Abuse and Alcoholism, Bethesda, MD.

National Institute on Alcohol Abuse and Alcoholism (2000) 10th Special Report to the U.S. Congress on Alcohol and Health. National Institute on Alcohol Abuse and Alcoholism, Bethesda, MD.

National Sleep Foundation (2000) Omnibus Sleep in America Poll. National Sleep Foundation, Washington, DC.

National Sleep Foundation Sleep and Teens Task Force (2000) Adolescent Sleep Needs and Patterns: Research Report and Research Guide. National Sleep Foundation, Washington, DC.

Pihl RO, Bruce KP (1995) Cognitive impairment in children of alcoholics. Alcohol Health Res World 19:142-147.

Pihl RO, Peterson JB (1991) Attention deficit hyperactivity disorder, childhood conduct disorders and alcoholism: is there an association? Alcohol Health Res World 15:25-31.

Robins LN, Helzer JE, Croughan JL, Ratcliff KS (1980) The NIMH Diagnostic Interview Schedule: Its History, Characteristics and Validity. Washington University School of Medicine, St. Louis, MO.
Roehrs T, Papineau K, Rosenthal L, Roth T (1999) Ethanol as a hypnotic in insomniacs: self administration and effects on sleep and mood. Neuropsychopharmacology 20:279-286.

Roehrs T, Roth T (2001) Sleep, sleepiness, sleep disorders and alcohol use and abuse. Sleep Med Rev 5:287-297.

Rubin DB (1976) Inference and missing data. Biometrika 63:581-592.

Schafer JL, Graham JW (2002) Missing data: our view of the state of the art. Psychol Methods 7:147-177.

Selzer ML, Vinokur A, van Rooijen L (1975) A self-administered Short Michigan Alcoholism Screening Test (SMAST). J Stud Alcohol 36:117_ 126.

Sher KJ (1994) Individual-level risk factors, in The Development of Alcohol Problems: Exploring the Biopsychosocial Matrix of Risk (Zucker RA, Boyd G, Howard J eds), pp 77-108. National Institute on Alcohol Abuse and Alcoholism, Bethesda, MD.

Skoloda TE, Alterman AI, Gottheil E (1979) Sleep quality reported by drinking and non-drinking alcoholics, in Addiction Research and Treatment: Converging Trends (Gottheil EL ed), pp 102-112. Pergamon Press, Elmsford, NY.

Tsuang MT, Lyons MJ, Meyer JM, Doyle T, Eisen SA, Goldberg J, True W, Lin N, Toomey R, Eaves L (1998) Co-occurrence of abuse of different drugs in men: the role of drug-specific and shared vulnerabilities. Arch Gen Psychiatry 55:967-972.

Tynjala J, Kannas L, Levalahti E (1997) Perceived tiredness among adolescents and its association with sleep habits and use of pyschoactive substances. J Sleep Res 6:189-198.

Vignau J, Bailly D, Duhamel A, Vervaecke P, Beuscart R, Collinet C (1997) Epidemiologic study of sleep quality and troubles in French secondary school adolescents. J Adolesc Health 21:343-350.

Weissman MM, Greenwald S, Nino-Murcia G, Dement WC (1997) The morbidity of insomnia uncomplicated by psychiatric disorders. Gen Hosp Psychiatry 19:245-250.

Wolfson AR, Carskadon MA (1998) Sleep schedules and daytime functioning in adolescents. Child Dev 69:875-887.

Wong MM, Nigg JT, Puttler LI, Fitzgerald HE, Zucker RA (2003) Developmental trajectories of ego undercontrol, externalizing problems and internalizing problems: Their effects on early onset of alcohol use. Alcohol Clin Exp Res 27(5) Supplement: 66A.

Zucker RA (1994) Pathways to alcohol problems and alcoholism: a developmental account of the evidence for multiple alcoholisms and for contextual contributions to risk, in The Development of Alcohol Problems: Exploring the Biopsychosocial Matrix of Risk (NIAAA Research Monograph No. 26; NIH Publication No. 94-3495), pp 255-289. Department of Health and Human Services, Rockville, MD.

Zucker RA, Ellis DA, Bingham CR, Fitzgerald HE (1996) The development of alcoholic subtypes: risk variation among alcoholic families during early childhood years. Alcohol Health Res World 20:46-54.

Zucker RA, Fitzgerald HE (1991) Early developmental factors and risk for alcohol problems. Alcohol Health Res World 15:18-24.

Zucker RA, Fitzgerald HE (2002) Assessment protocol: description of instruments and copies of contact schedules (appendix 9.3), in Family Study of Risk for Alcoholism Over the Life Course. Unpublished grant proposal. University of Michigan, Ann Arbor, MI.

Zucker RA, Fitzgerald HE, Noll RB (1990) Drinking and drug history (rev. ed., version 4). Unpublished instrument. Michigan State University, East Lansing, MI.

Zucker RA, Fitzgerald HE, Refior SK, Puttler LI, Pallas DM, Ellis DA (2000) The clinical and social ecology of childhood for children of alcoholics: description of a study and implications for a differentiated social policy, in Children of Addiction: Research, Health, and Policy Issues (Fitzgerald HE, Lester BM, Zuckerman BS eds), pp 1-30. Garland Press, New York.

Zucker RA, Wong MM, Puttler LI, Fitzgerald HE (2003) The effects of resilience on developmental outcomes of sons of alcohol, in Resilience and Vulnerability (Luthar SS ed), Cambridge University Press, New York. 